\title{
The prevalence and risk factors for depressive symptoms in frontline nurses under COVID-19 pandemic based on a large cross-sectional study using the propensity score-matched method
}

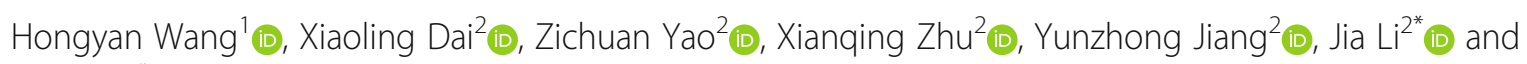
Bin $\operatorname{Han}^{2^{*}}$

\begin{abstract}
Introduction: To explore the prevalence of depressive symptoms and the associated risk factors in frontline nurses under COVID-19 pandemic.

Methods: This cross-sectional study was conducted from February 20, 2020 to March 20, 2020 and involved 562 frontline nurses. The effective response rate was $87.68 \%$. After propensity score matched, there were 498 participants left. Extensive characteristics, including demographics, dietary habits, life-related factors, work-related factors, and psychological factors were collected based on a self-reported questionnaire. Specific scales measured the levels of sleep quality, physical activity, depressive symptoms, perceived organization support and psychological capital. Adjusted odds ratios and 95\% confidence intervals were determined by binary paired logistic regression.
\end{abstract}

Results: Of the nurses enrolled in the study, 50.90\% had depressive symptoms. Three independent risk factors were identified: poor sleep quality ( $\mathrm{OR}=1.608,95 \% \mathrm{Cl}$ : 1.384-1.896), lower optimism of psychological capital $(\mathrm{OR}=0.879$, 95\% Cl: 0.805-0.960) and no visiting friend constantly (OR=0.513, 95\% Cl: 0.286-0.920).

Conclusions: This study revealed a considerable high prevalence of depressive symptoms in frontline nurses during the COVID-19 outbreak, and identified three risk factors, which were poor sleep quality, lower optimism of psychological capital, and no visiting friend constantly. Protecting mental health of nurses is important for COVID19 pandemic control and their wellbeing. These findings enrich the existing theoretical model of depression and demonstrated a critical need for additional strategies that could address the mental health in frontline nurses for policymakers.

Keywords: Depressive symptoms, Nurse, Psychological capital, Sleep quality, depression

\footnotetext{
* Correspondence: lijiacmu@163.com; hanbincmu81@163.com

${ }^{2}$ Department of Urology, Shengjing Hospital of China Medical University, No.

36, San Hao Street, Shenyang 110004, Liaoning, China

Full list of author information is available at the end of the article
}

(c) The Author(s). 2021 Open Access This article is licensed under a Creative Commons Attribution 4.0 International License, which permits use, sharing, adaptation, distribution and reproduction in any medium or format, as long as you give appropriate credit to the original author(s) and the source, provide a link to the Creative Commons licence, and indicate if changes were made. The images or other third party material in this article are included in the article's Creative Commons licence, unless indicated otherwise in a credit line to the material. If material is not included in the article's Creative Commons licence and your intended use is not permitted by statutory regulation or exceeds the permitted use, you will need to obtain permission directly from the copyright holder. To view a copy of this licence, visit http://creativecommons.org/licenses/by/4.0/. The Creative Commons Public Domain Dedication waiver (http://creativecommons.org/publicdomain/zero/1.0/) applies to the data made available in this article, unless otherwise stated in a credit line to the data. 


\section{Introduction}

Coronavirus disease 2019 (COVID-19), with an epicentre in Wuhan of China, has spread globally [1]. The World Health Organization Emergency Committee declared COVID-19 is an international public health emergency and outbreak in late January 2020 [2]. By May 1, 2020, there were 3,067,015 confirmed COVID-19 cases, including 214,375 associated deaths [2]. Such large-scale international public health threat presented severe challenges for medical staff. For example, frontline medical staff are under both physical and psychological pressure, staff members who experienced symptoms of depression were at increased risk of making errors in patient care [3]. Maintaining good mental health among medical staff is essential to prevent infectious disease spread and ensuring long-term wellbeing of staff [4]. Therefore, mental health of frontline medical staff should be supported during the outbreak of COVID-19.

Depression is characterized by low or absent positive feelings, and it can result in substantial impairments in social relationships, such as divorce, distancing from relatives or friends, limited social support, less success in the workplace, and illness [5]. Depression may also lead to suicidal ideation. Those who recover from depression still show impaired function in social and occupational domains [6]. As reported in the Global Burden of Disease study [7], the number of cases of depression worldwide increased from 172 million in 1990 to 258 million in 2017, representing a $49.86 \%$ increase during the study period. A survey of $>50,000$ medical staff from Australia demonstrated an increased incidence of depression along with a two-fold increased incidence of suicidal ideation compared with the general population [8].

Nurses appear to be at an increased risk of developing mental disorders, which may reflect longer hours at work, separation from their families, and caring for a large number of patients [9]. Depression impairs both psychological and physical functions, which diminish professional performance, affects the quality of patient treatment outcomes, and provokes conflicts with patients, or colleagues [10]. Therefore, depression is a critical issue, not only for nurses themselves, but also for the health and safety of the patients they treat [11].

As a new an international public health emergency, COVID-19 has generated great research interest. However, data on the prevalence and risk factors of depressive symptoms among frontline nurses during the COVID-19 outbreak are none in China. Therefore, we developed a survey to determine the prevalence of depressive symptoms and its associated risk factors in this population.

\section{Methods}

Study design

This cross-sectional study was based on WeChat-based survey programme Questionnaire. From February 20, 2020 to March 20, 2020, a total of 641 frontline nurses responding to the COVID-19 outbreak participated in the present study. Data from participants who did not provide information on any of the variables of interest were excluded $(n=79)$. Overall, data from 562 participants were included in the final analyses. The average questionnaire spent 10 to $15 \mathrm{~min}$.

\section{Inclusion and exclusion criteria}

The inclusion criteria were as follows: occupationally active nurses who were employed in our hospitals. The following exclusion criteria were used: nurses who had participated in work less than 3 months or refused to participate in this program. Nurses who did not provide complete psychological questionnaire or clinical data were excluded either. Finally, effective responses were obtained from 562 individuals (effective response rate: $87.68 \%)$. A flow chart illustrating the process is detailed in Fig. 1.

\section{Measurement of characteristics}

In this study, demographic characteristics included age, gender, BMI $\left(\mathrm{kg} / \mathrm{m}^{2}\right)$. Dietary habits included smoking status (current vs. never plus former), alcohol habit (current vs. never plus former), coffee habit (current vs. never plus former); Life related factors included sleep quality (PSQI, Pittsburgh sleep quality index scores), physical activity (IPAQ, International Physical Activity Questionnaire, Mets $\times$ hour/week), have religions (yes vs. no), marital status (single/ divorce/ separation/ widow vs. married /cohabitation), have siblings (yes vs. no), household income monthly (RMB, yuan) was categorized as, $<5000, \geqq 5000,<10,000$ and $\geqq 10,000$, experienced major life events (yes vs. no), visiting friend constantly (yes vs. no). Smoking habit was categorized as current smoker ( $\geqq 1$ cigarette per day and last $\geqq 6$ months), former smoker (stop smoking $\geqq 6$ months), and never smoker. Alcohol habit and coffee habit as categorized as current drinker ( $\geqq 1$ time per day and last $\geqq 6$ months), former drinker (stop drinking $\geqq 6$ months), and never drinker.

Work related factors included years of service $(\leq 5$ years vs. 5 years $<$ and $\leq 10$ years vs. $>10$ years), specialty (surgery vs. internal medicine vs. obstetrics and gynecology vs. pediatrics vs. others), working duration (< $40 \mathrm{~h}$ /week vs. 40-60 h/week vs. > $60 \mathrm{~h} /$ week), and night shifts (times/month).

Psychological characteristics included Perceived Organization Support (POS) scale, Psychological Capital 
This study was conducted in Feburary, 2020 (641 nurses in total)

9 refused to participate response rate $(98.60 \%, 632 / 641)$

70 nurses excluded due to missing clinical data 18 missing depression symptoms

7 missing BMI

6 missing religion

19 missing household income

11 missing PSQI

9 missing working duration

\section{2 nurses included in final analysis (effective response rate: $87.68 \%, 562 / 641$ )}

Fig. 1 Flowchart of this study. Abbreviations: BMI, body mass index; PSQI, Pittsburgh sleep quality index

Questionnaire (PsyCap), and Patient Health Questionnaire (PHQ9).

Physical activity (PA) in the most recent week was assessed using the short form of the International Physical Activity Questionnaire (IPAQ) [12]. The questionnaire asked whether subjects had performed any activities from the following categories during the previous week: walking; moderate activity (household activity or child care); vigorous activity (running, swimming, or other sports activities). Metabolic equivalent (MET) hours per week were calculated using corresponding MET coefficients (3.3, 4.0, and 8.0, respectively) according to the following formula: MET coefficient of activity $\times$ duration $(\mathrm{h}) \times$ frequency (days). Total PA levels were assessed by combining separate scores for different activities.

Sleep quality was measured by Pittsburgh sleep quality index (PSQI),which was developed by Buysse et al. [13]. It is a self-report on subjective sleep quality over the last 4 weeks with 18 questions. The first four questions enquire about times (bed time, number of minutes it took for the participant to fall asleep, get up time, and hours of sleep per night). The next 10 questions ask how often the participant had trouble sleeping because of different reasons (e.g. woke up in the middle of the night, need to go to the bathroom, cough, and bad dreams). Each of these questions must be answered on a 4-point scale ranging from "never" to "three times or more a week." Additional questions include a subjective rating of the participants' sleep quality (4-point scale from "very good" to "very bad"), the use of sleep medication, and trouble staying awake during the day (4-point scale ranging from "never" to "three times or more a week"). The final question asks if it has been a problem for the participant to keep up enough enthusiasm for getting things done (4-point scale ranging from "no problem at all" to "a very big problem"). The 18 items of the PSQI form seven-component score ranging from 0 to 3 (sleep quality, sleep latency, sleep duration, sleep efficiency, sleep disturbances, sleep medication, and daytime dysfunction) that can be summed up to a general score. Higher scores represent worse sleep quality. Poor sleep quality is indicated by total score of 6 or greater.

Experienced major life events included separation/divorce, death or serious illness of closely family members, serious injury/traffic accident, violence, unemployment, natural disasters, death or serious illness of partner, serious conflict with family, medical disputes, or income decrease/debt.

\section{Measurement of organization support}

The Chinese version of the Perceived Organization Support Questionnaire (POS) was utilized to measure the level of organization support [14]. There were nine items, The score of each item is given on a 7-point Likert-type scale in accordance with the nurses' personal experiences, ranging from 1 (very strongly disagree) to 7 (very strongly agree). The total score ranges from 9 to 63 , with a higher score indicating higher social support. 
The POS has good reliability and validity among various Chinese.

\section{Measurement of psychological capital}

PsyCap was evaluated by the Chinese version of the 24item Psychological Capital Questionnaire (PCQ) [15]. The PCQ is comprised of four dimensions: self-efficacy (6 items), hope (6 items), resilience (6 items), and optimism (6 items). Each question is scored from 1 (strongly disagree) to 6 (strongly agree). Higher scores indicate higher levels of psychological capital. The PCQ has demonstrated adequate reliability and validity in multiple samples [16].

\section{Measurement of depressive symptoms}

Depressive symptoms were measured by clinically validated scales for PHQ09. The PHQ09 scale comprises 9 items, and each item includes 4-point Likert-type scale responses that describe the frequency of subjects' feelings in the past Two week ranging from 0 to 3 . The summed score ranges from 0 to 27 , with a higher score indicating more severe depressive symptoms. The presence of depressive symptoms was defined as a PHQ09 score $\geqq 5$. The Chinese PHQ09 scale has been widely used in previous studies [17].

\section{Propensity score-matching}

We used the propensity score-matching (PSM) method to adjust baseline confounding variables between the depressive symptoms and non-depressive symptoms nurses in an effort to derive more accurate conclusions.
Multivariate logistic regression analysis was used to determine propensity scores for each participant based on gender, age, body mass index, smoking status, alcohol habit, and drinking coffee habit, which were demographics or life habit. For assessing the calibration of the logistic regression model, the Hosmer-Lemeshow goodnessof-fit test $(P=0.83)$ was performed for this logistic regression model [a high $P$ value $(>0.05)$ was interpreted as a good fit for the models]. Depressive symptoms and non-depressive symptoms groups were matched $1: 1$ by using a caliper width 0.2 of the standard deviation of the logit of the propensity score through the nearest neighbor matching, as this value minimized the mean squared error of the estimated treatment effect in several scenarios. (Fig. 2). The balance diagnostics completed for the propensity score method and showed no difference of covariates between two groups (|Standardized Difference| of all covariates was $<0.1)[18]$.

\section{Statistical analysis}

Sample size calculation was based on the prevalence of depression (The proportion is 0.27) [19-21]. The 95\% confidence interval width is 0.08 , Type I error $\alpha$ was 0.05 , two-tailed $P$-value was $<0.05$, was calculated by PASS 11.0. We determined a minimum sample size of 496 participants.

Data were analyzed by SPSS 22.0 for Windows (SPSS Inc., Chicago, IL, USA). Continuous variables were presented as the median (interquartile range). Categorical variables were reported as the number (percentage). Univariate analysis was conducted by binary paired
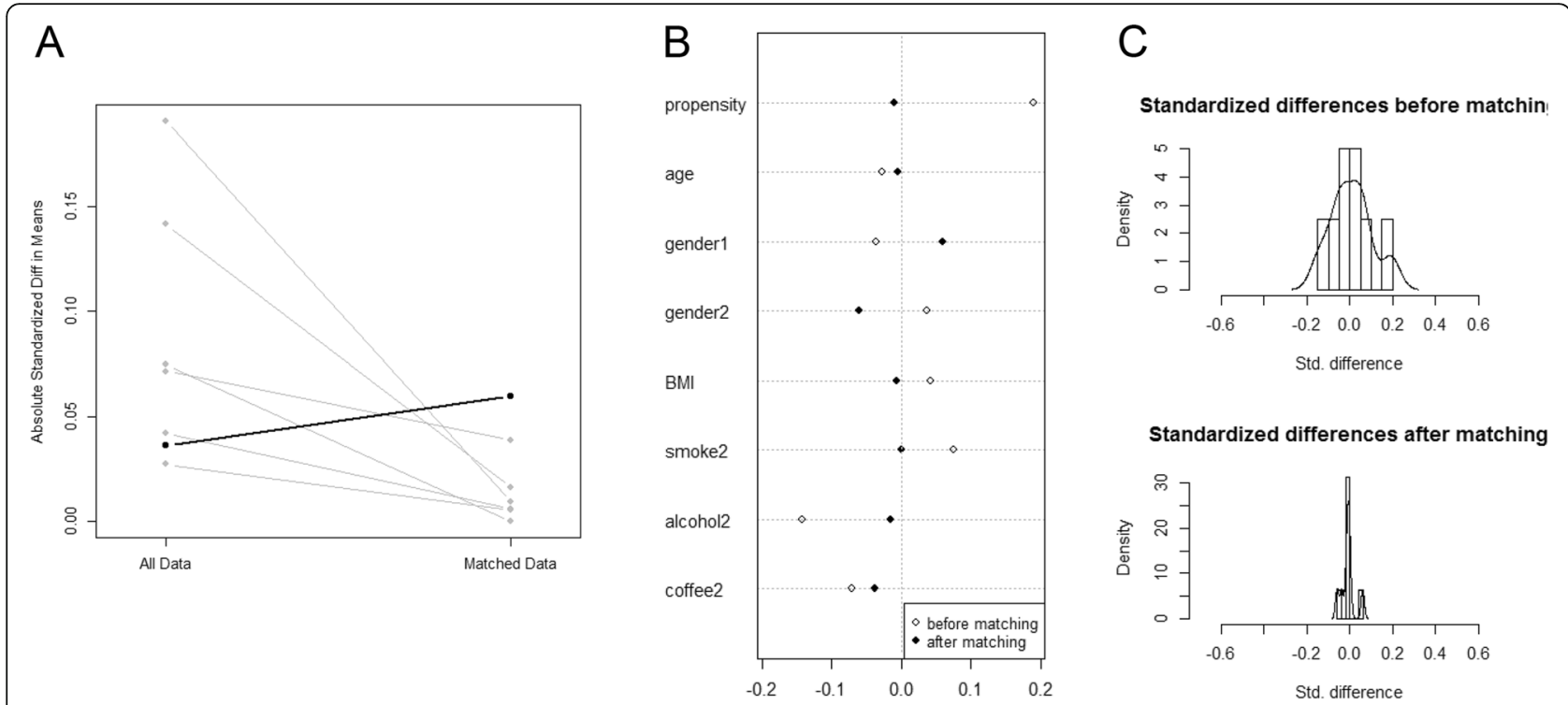

Fig. 2 Plot of propensity score-matched in this study. a line plot foe individual differences of depressive symptoms. $\mathbf{b}$ dot-plot for standardized mean differences of depressive symptoms. c histogram for standardized mean differences (before and after) of depressive symptoms 
logistic regression model. Baseline variables that were considered clinically relevant or that had a $p$-value < 0.15 in the univariate analysis were included in a multivariate binary paired logistic regression model. Adjusted odds ratios and $95 \%$ confidence intervals $(95 \% \mathrm{CI}$ ) were also determined after adjusting for potential confounders by binary paired logistic regression. Cutoff values and the area under the curve (AUC) for continuous variables which were independent risk factors for depressive symptoms were calculated through receiver operating characteristic curve analysis. A p-value of less than 0.05 was considered statistically significant.

\section{Results}

There were 562 nurses included in this study finally (Fig. 1). The demographic characteristics, dietary habits, life related factors, work related factors, and psychological characteristics were displayed in Table 1 . Of these nurses, they reported $50.90 \%$ (286) with depressive symptoms. The average age and BMI were 35.00 and $21.90 \mathrm{~kg} / \mathrm{m}^{2}$, respectively. The most nurses were female gender, drinking alcohol, drinking coffee, married status, and never smoker, had no religion, no experienced major life events, $\geqq 10,000$ yuan/month household income, and 40-60 h/week working duration. The ratio visiting friends constantly, have siblings and years of service were balanced among each groups. The average of PSQI, PA, night shifts, POS (selfefficacy, hope, resilience, and optimism), and PsyCap, were also presented in Table 1 specifically.

A balance of baseline confounding variables between the two groups (depressive symptoms vs. non-depressive symptoms) after PSM was achieved (Fig. 2). There were 498 nurses left finally. In matched group, depressive nurses had higher score of PSQI, and lower scores of POS and PsyCap. They also had higher ratio of experienced major life events and 5 to 10 years of service. They had lower ratio of have siblings, married and visiting friends constantly. All above variables were statistical differences in univariate analysis and then included multivariate analysis, see details in Table 2.

Based on multivariate paired logistic regression, three independent risk factors for depressive symptoms were identified, as follows: poor sleep quality $(\mathrm{OR}=1.608)$, lower optimism of PsyCap (OR $=0.879)$, and no visiting friends constantly $(\mathrm{OR}=0.513)$, see details in Table 3 .

In addition, the optimal cutoff point of continuous risk factors were analyzed by the receiver operating characteristic curve. The cutoff value for PSQI and optimism of PsyCap were 5 scores and 25 scores, see Fig. 3.

\section{Discussion}

To the best of our knowledge, the present study is the first study to explore the prevalence and risk factors of depressive symptoms among frontline nurses responding to the COVID-19 outbreak in China. Although medical staff was not the main route of transmission in the case of COVID-19, they were in high-risk work environment. In addition, due to a large number of intensive care and emergency patients affected by this new infectious disease, therefore, emotional supports and encouragement for overcoming COVID-19 were urgently required. This study revealed a considerable high prevalence of depressive symptoms in this population, and there were three risk factors for depressive symptoms, which were poor sleep quality, lower optimism of psychological capital, and visiting friend rarely. In this study, $50.90 \%$ of nurses reported depressive symptoms. These results show that frontline nurses responding to the COVID19 outbreak are almost more than ten times as likely to experience depressive symptoms compared to the general population, as demonstrated in a nationally representative face-to-face household survey in Germany between 2003 and 2008 ( $n=5018$, depressive symptoms rate $=5.6 \%)[22]$.

Loneliness, contrary to human nature due to the disposition toward social communication and unity is a negative situation occurring due to the insufficient quality and quantity of social relationship networks of an individual. Therefore, visiting friend constantly is usually a positive source of psychological supports. In line with this, visiting friend constantly was an independent factor for depressive symptoms in frontline nurses. Erzen et al. also found that loneliness as a negative emotion was considered to be a predisposing factor in depression in a meta analysis, which included 40,068 individuals [23].

This study demonstrated that poor sleep quality is positively associated with the prevalence of depressive symptoms in nurses. Previous studies have also shown that poor sleep quality is associated with a higher prevalence of depressive symptoms in different population, such as undergraduate students [24] and adolescents [25]. Harvey et al. [26] suggested that simply improving sleep can substantially reduce depressive symptoms. There are several mechanisms underlying the observed positive associations between poor sleep quality and the prevalence of depressive symptoms. First, sleep disturbance is associated with an increase in markers of systemic inflammation and pro-inflammatory cytokines produced by immune cells [27]. Immune signaling to the brain can lead to an exacerbation of the development of depressive symptoms in vulnerable individuals [28]. Second, serotonergic neurotransmission can interact with other brain areas modulating circadian rhythm and sleep [29]. In addition, the pathophysiology of depression is strongly linked to impairment in serotonin neurotransmission [30]. Third, previous research has suggested that circadian preferences may have an important role in the connection between sleep and depression [31]. 
Table 1 Characteristics of nurses before and after PSM by depressive symptoms in this study during the COVID-19 outbreak

\begin{tabular}{|c|c|c|}
\hline Variables & $\begin{array}{l}\text { Before PSM } \\
562(100 \%) \text { nurses }\end{array}$ & $\begin{array}{l}\text { After PSM } \\
498(100 \%) \text { nurses }\end{array}$ \\
\hline Depressive symptoms (yes) & $286(50.90)$ & 1:1 PSM \\
\hline \multicolumn{3}{|l|}{ Demographic characteristics } \\
\hline Age (years) & $35.00(34.00,36.00)$ & $35.00(34.00,36.00)$ \\
\hline Sex (male vs.female) & $118(21.00) / 444(79.00)$ & $100(20.10) / 398(79.90)$ \\
\hline BMI $\left(\mathrm{kg} / \mathrm{m}^{2}\right)$ & $21.90(19.80,24.23)$ & $22.00(19.97,24.22)$ \\
\hline \multicolumn{3}{|l|}{ Dietary habits } \\
\hline Smoking habit (current yes) & $8(1.40)$ & $4(0.80)$ \\
\hline Alcohol habit (current yes) & $293(52.10)$ & $254(51.00)$ \\
\hline Coffee habit (current yes) & $430(76.50)$ & $380(76.30)$ \\
\hline \multicolumn{3}{|l|}{ Life related factors } \\
\hline Sleep quality (PSQI scores) & $6.00(4.00,7.00)$ & $6.00(4.00,7.00)$ \\
\hline Physical activity (IPAQ Metsxhour/week) & $9.90(6.60,23.73)$ & $9.90(6.60,23.21)$ \\
\hline Have religions (yes) & $25(4.40)$ & $21(4.20)$ \\
\hline \multicolumn{3}{|l|}{ Marital status } \\
\hline Single/divorce/separation/widow & $232(41.30)$ & $213(42.80)$ \\
\hline Married/cohabitation & $330(58.70)$ & $285(57.20)$ \\
\hline Have siblings (yes) & $268(47.70)$ & $229(46.00)$ \\
\hline \multicolumn{3}{|l|}{ Household income (Yuan/month) } \\
\hline$<5000$ & $33(5.90)$ & $27(5.40)$ \\
\hline$\geqq 5000,<10,000$ & $121(21.50)$ & $111(22.30)$ \\
\hline$\geqq 10,000$ & $408(72.60)$ & $360(72.30)$ \\
\hline Experienced major life events (yes) & $180(32.00)$ & $162(32.50)$ \\
\hline Visiting friend constantly (yes) & $259(46.10)$ & $231(46.40)$ \\
\hline \multicolumn{3}{|l|}{ Work related factors } \\
\hline \multicolumn{3}{|l|}{ Years of service } \\
\hline$\leq 5$ years & $158(28.10)$ & $146(29.30)$ \\
\hline 5 years $<$ and $\leq 10$ years & $239(42.50)$ & $216(43.40)$ \\
\hline$>10$ years & $165(29.40)$ & $136(27.30)$ \\
\hline \multicolumn{3}{|l|}{ Speciality } \\
\hline Surgery & $68(12.10)$ & $60(12.00)$ \\
\hline Internal medicine & $159(28.20)$ & $143(28.70)$ \\
\hline Obstetrics and Gynecology & $61(10.90)$ & $54(10.80)$ \\
\hline Pediatrics & $64(11.40)$ & $56(11.20)$ \\
\hline Others & $210(37.40)$ & $185(37.10)$ \\
\hline \multicolumn{3}{|l|}{ Working duration (hours/week) } \\
\hline $40-60 h$ & $409(72.80)$ & $357(71.70)$ \\
\hline$<40 \mathrm{~h}$ & $18(3.20)$ & $14(2.80)$ \\
\hline$>60 h$ & $135(24.00)$ & $127(25.50)$ \\
\hline Night shifts (times/month) & $1.00(1.00,4.00)$ & $1.00(1.00,4.00)$ \\
\hline \multicolumn{3}{|l|}{ Psychological characteristics } \\
\hline POS (scores) & $42.00(36.00,52.00)$ & $42.00(36.00,52.00)$ \\
\hline PsyCap-efficacy (scores) & $25.00(22.00,29.00)$ & $25.00(22.00,29.00)$ \\
\hline PsyCap-hope (scores) & $25.00(22.00,29.00)$ & $25.00(22.00,29.00)$ \\
\hline PsyCap-resiliency (scores) & $26.00(23.00,29.00)$ & $26.00(23.00,29.00)$ \\
\hline PsyCap-optimism (scores) & $25.00(22.00,28.00)$ & $25.00(22.00,28.00)$ \\
\hline
\end{tabular}

Continuous variables were reported median (interquartile range), categorical variables were reported as number (percentage)

Abbreviations: COVID-19 coronavirus disease 2019, PSM propensity score matching, BMI body mass index, PSQI, Pittsburgh sleep quality index, IPAQ International Physical Activity Questionnaires, POS Perceived Organization Support, PsyCap Psychological Capital 
Table 2 Univariate analysis of the risk factors for depressive symptoms of nurses before and after PSM during the COVID-19 outbreak

\begin{tabular}{|c|c|c|c|c|c|c|}
\hline \multirow[t]{2}{*}{ Variables } & \multicolumn{3}{|c|}{ PSM before 562 nurses } & \multicolumn{3}{|l|}{ PSM after 498 nurses } \\
\hline & $\begin{array}{l}\text { Depressive } \\
\text { symptoms } \\
286 \text { nurses }\end{array}$ & $\begin{array}{l}\text { Non-depressive } \\
\text { symptoms } \\
276 \text { nurses }\end{array}$ & $\mathrm{p}$ & $\begin{array}{l}\text { Depressive } \\
\text { symptoms } \\
249 \text { nurses }\end{array}$ & $\begin{array}{l}\text { Non-depressive } \\
\text { symptoms } \\
249 \text { nurses }\end{array}$ & $p$ \\
\hline \multicolumn{7}{|l|}{ Demographic characteristics } \\
\hline Age (years) & $35.00(34.00,36.00)$ & $35.00(34.00,36.00)$ & 0.750 & $35.00(34.00,36.00)$ & $35.00(34.00,36.00)$ & 0.953 \\
\hline Sex (male vs.female) & $58(20.30) / 228(79.70)$ & $60(21.70) / 216(78.30)$ & 0.671 & $53(21.30) / 196(78.70)$ & $47(18.90) / 202(81.10)$ & 0.378 \\
\hline $\mathrm{BMI}\left(\mathrm{kg} / \mathrm{m}^{2}\right)$ & $22.05(19.80,24.30)$ & $21.85(19.73,23.98)$ & 0.593 & $21.80(19.80,24.20)$ & $21.60(19.70,23.90)$ & 0.930 \\
\hline \multicolumn{7}{|l|}{ Dietary habits } \\
\hline Smoking habit (current yes) & $3(1.00)$ & $5(1.80)$ & 0.451 & $2(0.80)$ & $2(0.80)$ & 1.000 \\
\hline Alcohol habit (current yes) & $159(55.60)$ & $134(48.60)$ & 0.095 & $128(51.40)$ & $126(50.60)$ & 0.715 \\
\hline Coffee habit (current yes) & $223(78.00)$ & $207(75.00)$ & 0.406 & $192(77.10)$ & $188(75.50)$ & 0.663 \\
\hline \multicolumn{7}{|l|}{ Life related factors } \\
\hline Sleep quality (PSQI scores) & $7.00(5.00,9.00)$ & $4.00(3.00,6.00)$ & $<0.001$ & $7.00(5.00,9.00)$ & $4.00(3.00,6.00)$ & $<0.001$ \\
\hline $\begin{array}{l}\text { Physical activity (IPAQ } \\
\text { Metsxhour/week) }\end{array}$ & $8.96(6.60,22.73)$ & $11.55(6.60,26.55)$ & 0.443 & $8.25(6.60,21.28)$ & $11.55(6.60,26.40)$ & 0.195 \\
\hline Have religions (yes) & $16(5.60)$ & $9(3.30)$ & 0.185 & $12(4.80)$ & $9(3.60)$ & 0.493 \\
\hline Marital status & & & 0.061 & & & 0.026 \\
\hline $\begin{array}{l}\text { Single/divorce/separation/ } \\
\text { widow }\end{array}$ & $157(54.90)$ & $173(62.70)$ & & $119(47.80)$ & $94(37.80)$ & \\
\hline Married/cohabitation & $129(45.10)$ & $103(37.30)$ & & $130(52.20)$ & $155(62.20)$ & \\
\hline Have siblings (yes) & $122(42.70)$ & $146(52.90)$ & 0.015 & $99(39.80)$ & $130(52.20)$ & 0.009 \\
\hline $\begin{array}{l}\text { Household income } \\
\text { (Yuan/month) }\end{array}$ & & & 0.398 & & & 0.230 \\
\hline$<5000$ & $18(6.30)$ & $15(5.40)$ & & $16(6.40)$ & $11(4.40)$ & \\
\hline$\geqq 5000,<10,000$ & $65(22.70)$ & $56(20.30)$ & & $58(23.30)$ & $53(21.30)$ & \\
\hline$\geqq 10,000$ & $203(71.00)$ & $205(74.30)$ & & $175(70.30)$ & $185(74.30)$ & \\
\hline $\begin{array}{l}\text { Experienced major life } \\
\text { events(yes) }\end{array}$ & $103(36.00)$ & $77(27.90)$ & 0.040 & $93(37.30)$ & $69(27.70)$ & 0.020 \\
\hline $\begin{array}{l}\text { Visiting friend constantly } \\
\text { (yes) }\end{array}$ & $105(36.70)$ & $154(55.80)$ & $<0.001$ & $91(36.50)$ & $140(56.20)$ & $<0.001$ \\
\hline \multicolumn{7}{|l|}{ Work related factors } \\
\hline Years of service & & & 0.023 & & & 0.068 \\
\hline$\leq 5$ years & $65(22.70)$ & $93(33.70)$ & & $59(23.70)$ & $87(34.90)$ & \\
\hline 5 years $<$ and $\leq 10$ years & $132(46.20)$ & $107(38.80)$ & & $120(48.20)$ & $96(38.60)$ & \\
\hline$>10$ years & $89(31.10)$ & $76(27.50)$ & & $70(28.10)$ & $66(26.50)$ & \\
\hline Speciality & & & 0.646 & & & 0.702 \\
\hline Surgery & $37(12.90)$ & $31(11.20)$ & & $27(10.80)$ & $33(13.30)$ & \\
\hline Internal medicine & $81(28.30)$ & $78(28.30)$ & & $71(28.50)$ & $72(28.90)$ & \\
\hline Obstetrics and Gynecology & $30(10.50)$ & $31(11.20)$ & & $30(12.00)$ & $24(9.60)$ & \\
\hline Pediatrics & $33(11.50)$ & $31(11.20)$ & & $29(11.60)$ & $27(10.80)$ & \\
\hline Others & $105(36.80)$ & $105(38.10)$ & & $92(36.90)$ & $93(37.30)$ & \\
\hline Working duration (hours/week) & & & 0.405 & & & 0.485 \\
\hline $40-60 h$ & $204(71.30)$ & $205(74.30)$ & & $175(70.30)$ & $182(73.10)$ & \\
\hline$<40 \mathrm{~h}$ & $9(3.10)$ & $9(3.30)$ & & $7(2.80)$ & $7(2.80)$ & \\
\hline$>60 h$ & $73(25.50)$ & $62(22.50)$ & & $67(26.90)$ & $60(24.10)$ & \\
\hline Night shifts (times/month) & $1.00(1.00 .4 .00)$ & $1.00(1.00 .4 .00)$ & 0.503 & $1.00(1.00 .4 .00)$ & $1.00(1.00 .4 .00)$ & 0.515 \\
\hline
\end{tabular}


Table 2 Univariate analysis of the risk factors for depressive symptoms of nurses before and after PSM during the COVID-19 outbreak (Continued)

\begin{tabular}{|c|c|c|c|c|c|c|}
\hline \multirow{2}{*}{ Variables } & \multicolumn{3}{|c|}{ PSM before 562 nurses } & \multicolumn{3}{|c|}{ PSM after 498 nurses } \\
\hline & $\begin{array}{l}\text { Depressive } \\
\text { symptoms } \\
286 \text { nurses }\end{array}$ & $\begin{array}{l}\text { Non-depressive } \\
\text { symptoms } \\
276 \text { nurses }\end{array}$ & $p$ & $\begin{array}{l}\text { Depressive } \\
\text { symptoms } \\
249 \text { nurses }\end{array}$ & $\begin{array}{l}\text { Non-depressive } \\
\text { symptoms } \\
249 \text { nurses }\end{array}$ & $p$ \\
\hline \multicolumn{7}{|l|}{ Psychological characteristics } \\
\hline POS (scores) & $39.00(33.00,48.00)$ & $46.00(38.00,54.00)$ & $<0.001$ & $39.00(32.00,47.00)$ & $46.00(38.00,54.00)$ & $<0.001$ \\
\hline PsyCap-efficacy (scores) & $24.00(21.00,27.00)$ & $28.00(24.00,30.00)$ & $<0.001$ & $24.00(21.00,27.00)$ & $27.00(24.00,30.00)$ & $<0.001$ \\
\hline PsyCap-hope (scores) & $24.00(20.00,27.00)$ & $28.00(24.00,30.00)$ & $<0.001$ & $24.00(20.00,27.00)$ & $28.00(24.00,30.00)$ & $<0.001$ \\
\hline PsyCap-resiliency (scores) & $24.00(21.00,27.00)$ & $27.00(24.00,30.00)$ & $<0.001$ & $24.00(22.00,27.00)$ & $27.00(24.00,30.00)$ & $<0.001$ \\
\hline PsyCap-optimism (scores) & $24.00(21.00,27.00)$ & $27.00(24.00,30.00)$ & $<0.001$ & $24.00(21.00,27.00)$ & $27.00(24.00,30.00)$ & $<0.001$ \\
\hline
\end{tabular}

Continuous variables were expressed as median (interquartile range); categorical variables were reported asnumber (percentage). $\mathrm{P}$ value was analyzed by univariate paired conditional logistic regression

Abbreviations: COVID-19 coronavirus disease 2019, PSM propensity score matching, BMI body mass index, PSQI, Pittsburgh sleep quality index, IPAQ International

Physical Activity Questionnaires, POS Perceived Organization Support, PsyCap Psychological Capital

Psychological capital (PsyCap) is a positive organizational behavior approach, which has been demonstrated as a positive resource of psychological capacities [15]. PsyCap consists of the four-dimensional resources, which are self-efficacy, hope, optimism, and resilience. Optimism includes the dispositional optimistic look towards the future. It has been reported that individuals with higher levels of PsyCap are able to have more confidence and make greater efforts to pursue success, and perceive positive expectations and attributes regarding consequences [32]. This study demonstrated that lower optimism was a significant risk factor for depressive symptoms in nurses. In line with this, Liu et al. [33] found that PsyCap could be a positive resource for combating depressive symptoms in physicians, which included 998 physicians in a cross-sectional survey of China. According to the study of Heinitz [34], optimism predicts depression. Hence, in a direct comparison, optimism appears to be the most relevant for depression of the four constructs.

There were several limitations in this study. First, this was a cross-sectional research that was unable to assess the causal relationships among study variables. Therefore, a longitudinal study should be carried out to verify our conclusions. Second, psycho-social variables were measured using self-report questionnaires, which might have recall and reporting bias. Third, depressive symptoms was confirmed by PHQ09, not a clinical diagnosis, which may influence the estimates. Since the questionnaire relies on patient self-report, all responses were not verified by the clinician. Moreover, diagnoses of Major Depressive Disorder or Other Depressive Disorder also require impairment of social, occupational, or other important areas of functioning and ruling out normal bereavement, a history of a Manic Episode (Bipolar Disorder), and a physical disorder, medication, or other drug as the biological cause of the depressive symptoms. Fourth, there were unmeasured confounding factors that contributed to the observed associations. Fifth, the participants of this study were recruited from one center. Nevertheless, this is the first study to explore the prevalence of depressive symptoms and its associated risk factors in frontline nurses during the COVID-19 outbreak from China.

Table 3 Multivariate analysis of the risk factors for depressive symptoms of nurses before and after PSM during the COVID-19 outbreak

\begin{tabular}{|c|c|c|c|c|}
\hline \multirow[t]{2}{*}{ Variables } & \multicolumn{2}{|l|}{ PSM before } & \multicolumn{2}{|l|}{ PSM after } \\
\hline & OR $(95 \% \mathrm{Cl})$ & $p$ & OR $(95 \% \mathrm{Cl})$ & $p$ \\
\hline Sleep quality (PSQI scores) & $1.491(1.354,1.640)$ & $<0.001$ & $1.608(1.384,1.896)$ & $<0.001$ \\
\hline Have siblings (no vs. yes) & $1.743(1.164,2.610)$ & 0.007 & $1.314(0.558,3.093)$ & 0.531 \\
\hline Visiting friend constantly (yes vs. no) & $0.601(0.401,0.903)$ & 0.014 & $0.513(0.286,0.920)$ & 0.025 \\
\hline PsyCap-hope (scores) & $0.899(0.850,0.952)$ & $<0.001$ & $0.988(0.887,1.099)$ & 0.819 \\
\hline PsyCap-optimism (scores) & $0.908(0.853,0.966)$ & 0.002 & $0.879(0.805,0.960)$ & 0.004 \\
\hline
\end{tabular}

The odds ratio and $95 \%$ confidence interval were analyzed by multivariate paired logistic regression

Abbreviations: COVID-19 coronavirus disease 2019, PSM propensity score matching, OR odds ratio, CI confidence interval, PSQI Pittsburgh sleep quality index PsyCap Psychological Capital 


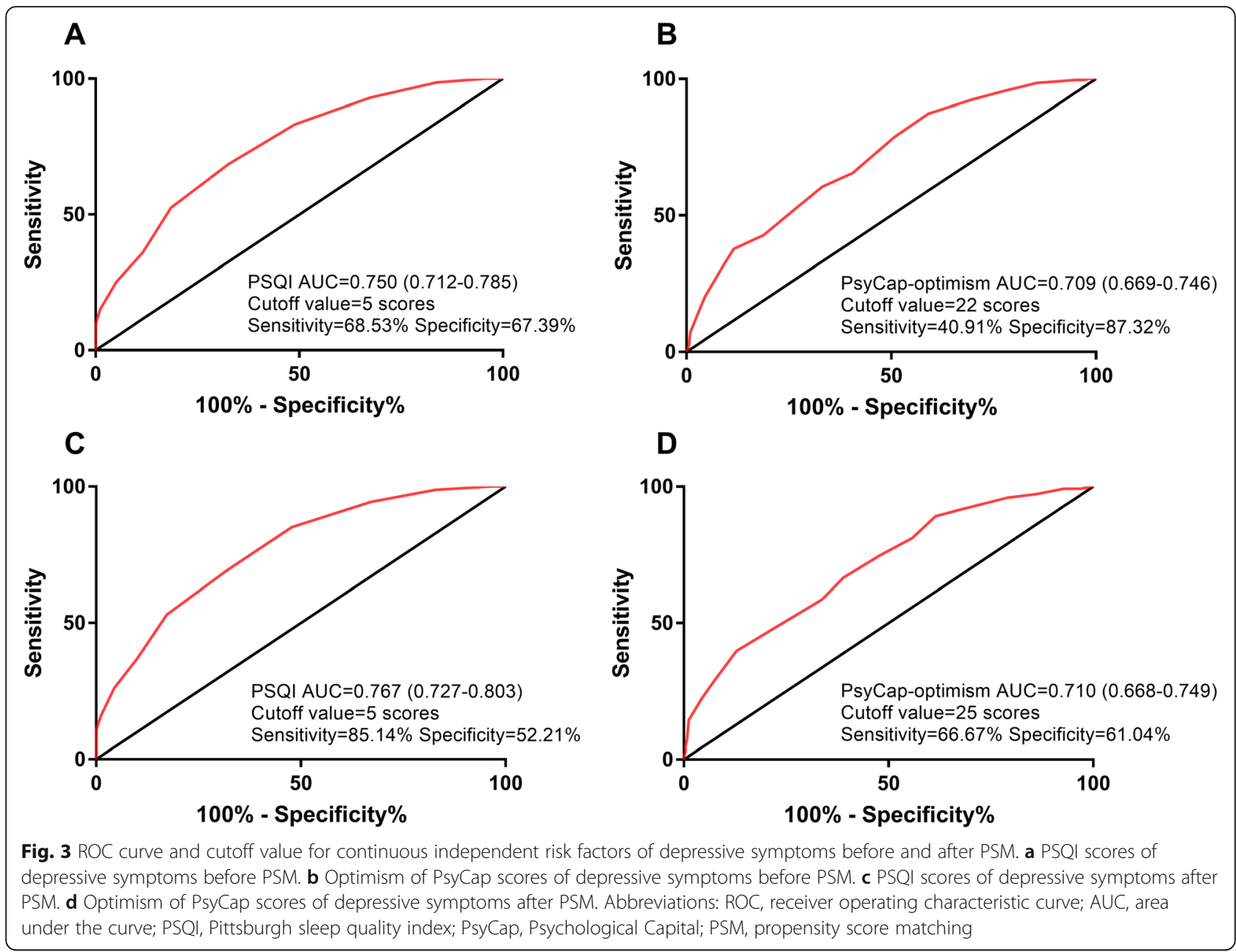

\section{Conclusions}

This study revealed a considerable high prevalence of depressive symptoms in frontline nurses during the COVID-19 outbreak, and identified three risk factors, which were poor sleep quality, lower optimism of psychological capital, and visiting friend rarely. Protecting mental health of nurses is important for COVID-19 pandemic control and their wellbeing. These findings enrich the existing theoretical model of depression and demonstrated a critical need for additional strategies that could address the mental health in frontline nurses for policymakers.

\section{Abbreviations}

PSQI: Pittsburgh Sleep Quality Index; PHQ-9: Patient Health Questionnaire-9; OR: Odds ratio; Cl: Confidence interval; BMI: Body mass index;

IPAQ: International Physical Activity Questionnaire; MET: Metabolic equivalent

\section{Acknowledgements}

We thank International Science Editing (http://www. internationalscienceediting.com) for editing this manuscript. The authors would like to thank all of the study participants.
Data availability statements

The datasets used and analysed during the current study are available from the corresponding author on reasonable request.

\section{Disclosure of potential conflicts of interest}

The authors (Hongyan Wang, Xiaoling Dai, Zichuan Yao, Xianging Zhu, Yunzhong Jiang, Jia Li, and Bin Han.) declare that they have no competing interests.

\section{Financial disclosures}

Bin Han and Jia Li certifies that all conflicts of interest, including specific financial interests, relationships and affiliations relevant to the subject matter or materials discussed in the manuscript (eg, employment/affiliation, grants or funding, consultancies, honoraria, stock ownership or options, expert testimony, royalties, or patents filed, received, or pending) are none.

\section{Authors' contributions}

$\mathrm{BH}$ and $J \mathrm{~L}$ had full access to all the data in the study and takes responsibility for the integrity of the data and the accuracy of the data analysis. $\mathrm{BH}$ and $\mathrm{JL}$ were responsible for study concept and design. HW, XD, ZY, XZ, and YJ were responsible for acquisition of data, analysis and interpretation of data. HW, $\mathrm{XD}, \mathrm{BH}$, and $\mathrm{J}$ were responsible for drafting of the manuscript and critical revision of the manuscript. XD, and $\mathrm{JL}$ were responsible for statistical analysis. All authors critically reviewed the paper and approved the final version.

Funding

Not applicable. 


\section{Declarations}

\section{Ethics approval and consent to participate}

Ethical approval was approved by the Institutional Research and Ethics Committee of the Shengjing Hospital Affiliated China Medical University in Shengyang, China. This study were carried out in accordance with STROCSS criteria and the Declaration of Helsinki. All participants provided written informed consent before participating in the study.

\section{Consent for publication}

Not applicable.

\section{Author details}

'Department of Thoracic Surgery, Shengjing Hospital of China Medical University, Shenyang, China. ${ }^{2}$ Department of Urology, Shengjing Hospital of China Medical University, No. 36, San Hao Street, Shenyang 110004, Liaoning, China.

Received: 30 October 2020 Accepted: 26 February 2021

Published online: 16 March 2021

\section{References}

1. Wu JT, Leung K, Leung GM. Nowcasting and forecasting the potential domestic and international spread of the 2019-nCoV outbreak originating in Wuhan, China: a modelling study. LANCET. 2020;395:689-97.

2. WHO. 2020. Novel Coronavirus (2019-nCov) Situation Report-41.https:// www.who.int/docs/default-source/coronaviruse/situation-reports/20200301sitrep-41-covid-19.pdf?sfvrsn=6768306d_2 (accessed 1 May 2020).

3. Garrouste-Orgeas M, Perrin M, Soufir L, et al. The latroref study: medical errors are associated with symptoms of depression in ICU staff but not burnout or safety culture. INTENS CARE MED. 2015;41:273-84.

4. Kang L, Li Y, Hu S, et al. The mental health of medical workers in Wuhan, China dealing with the 2019 novel coronavirus. Lancet Psychiat. 2020;7:e14.

5. Gotlib IHHC. Handbook of depression. New York: Guilford Publications; 2009

6. Romera I, et al. Social and occupational functioning impairment in patients in partial versus complete remission of a major depressive disorder episode. A six-month prospective epidemiological study. Eur Psychiatry. 2010;25(1): 58-65.

7. Liu Q, He H, Yang J, Feng X, Zhao F, Lyu J. Changes in the global burden of depression from 1990 to 2017: findings from the global burden of disease study. J Psychiatr Res. 2020;126:134-40.

8. National Mental Health Survey of Doctors and Medical Students, Australia. http://www.beyondblue.org.au/docs/default-source/default-document-libra ry/bl1132-report-nmhdmss-full-report_web, 2011

9. Donisi $\mathrm{V}$, et al. Prediction of community mental health service utilization by individual and ecological level socio-economic factors. Psychiatry Res. 2013; 209(3):691-8.

10. de Oliveira GJ, et al. The prevalence of burnout and depression and their association with adherence to safety and practice standards: a survey of United States anesthesiology trainees. Anesth Analg. 2013;117(1):182-93.

11. Wang JN, et al. Prevalence and associated factors of depressive symptoms among Chinese doctors: a cross-sectional survey. Int Arch Occup Environ Health. 2010;83(8):905-11.

12. Craig $\mathrm{CL}$, et al. International physical activity questionnaire: 12-country reliability and validity. Med Sci Sports Exerc. 2003;35(8):1381-95.

13. Buysse DJ, et al. The Pittsburgh sleep quality index: a new instrument for psychiatric practice and research. Psychiatry Res. 1989;28(2):193-213.

14. Eisenberger R. S.F., perceived organizational support: fostering enthusiastic and productive employees. J Appl Psychol. 2011:3(71):500-7.

15. Luthans F. A.B.A.J., Positive psychological capital: measurement and relationship with performance and satisfaction. Pers Psychol. 2007;60: 541-72.

16. Zhang K, Z.S.D.Y. Positive psychological capital: measurement and its association with mental health. Stu Psychol Behav. 2010;8:58-64.

17. Kroenke K, Spitzer RL, Williams JB. The PHQ-9: validity of a brief depression severity measure. J Gen Intern Med. 2001;16(9):606-13.

18. Austin PC. An introduction to propensity score methods for reducing the effects of confounding in observational studies. Multivariate Behav Res. 2011:46(3):399-424.

19. Fleiss $J L$, Levin B, Paik MC. Statistical methods for rates and proportions. 3rd ed. New York: Wiley; 2003.
20. Newcombe RG. Two-sided confidence intervals for the single proportion: comparison of seven methods. Stat Med. 1998;17(8):857-72.

21. Mira JJ, Carrillo I, Guilabert M, et al. Acute stress of the healthcare workforce during the COVID-19 pandemic evolution: a cross-sectional study in Spain. BMJ Open. 2020;10(11):e042555.

22. Kocalevent RD, Hinz A, Brahler E. Standardization of the depression screener patient health questionnaire (PHQ-9) in the general population. Gen Hosp Psychiatry. 2013;35(5):551-5.

23. Erzen $\mathrm{E}$, Çikrikci Ö. The effect of loneliness on depression: a meta-analysis. Int J Soc Psychiatry. 2018;64(5):427-35.

24. Bhandari PM, et al. Sleep quality, internet addiction and depressive symptoms among undergraduate students in Nepal. BMC Psychiatry. 2017; 17(1):106.

25. Raniti MB, et al. Sleep duration and sleep quality: associations with depressive symptoms across adolescence. Behav Sleep Med. 2017:15(3):198-215.

26. UC Berkeley Graduate Assembly. Graduate Student Happiness and Wellbeing Report. http://ga.berkeley.edu/wellbeingreport, 2014.

27. Irwin MR, Olmstead R, Carroll JE. Sleep disturbance, sleep duration, and inflammation: a systematic review and Meta-analysis of cohort studies and experimental sleep deprivation. Biol Psychiatry. 2016;80(1):40-52.

28. Dantzer $R$, et al. From inflammation to sickness and depression: when the immune system subjugates the brain. Nat Rev Neurosci. 2008;9(1):46-56.

29. Ursin R. Serotonin and sleep. Sleep Med Rev. 2002;6(1):55-69.

30. Mahar I, et al. Stress, serotonin, and hippocampal neurogenesis in relation to depression and antidepressant effects. Neurosci Biobehav Rev. 2014;38: 173-92.

31. Dinis J, Braganca M. Quality of sleep and depression in college students: a systematic review. Sleep Sci. 2018;11(4):290-301.

32. Wang $Z$, et al. Associations between occupational stress, burnout and wellbeing among manufacturing workers: mediating roles of psychological capital and self-esteem. BMC Psychiatry. 2017;17(1):364.

33. Liu $L$, et al. The mediating role of psychological capital on the association between occupational stress and depressive symptoms among Chinese physicians: a cross-sectional study. BMC Public Health. 2012;12:219.

34. Heinitz K, et al. Positive organizational behavior: longitudinal effects on subjective well-being. PLoS One. 2018;13(6):e0198588.

\section{Publisher's Note}

Springer Nature remains neutral with regard to jurisdictional claims in published maps and institutional affiliations.
Ready to submit your research? Choose BMC and benefit from:

- fast, convenient online submission

- thorough peer review by experienced researchers in your field

- rapid publication on acceptance

- support for research data, including large and complex data types

- gold Open Access which fosters wider collaboration and increased citations

- maximum visibility for your research: over $100 \mathrm{M}$ website views per year

At BMC, research is always in progress.

Learn more biomedcentral.com/submissions 